\title{
Pemodelan Hubungan Antara Kualiti Perkhidmatan, Kesan Alam Sekitar, Sikap dan Keinginan untuk Menggunakan Park-and-Ride
}

\author{
(Modelling of Relationship Between Service Quality, Environmental Impact, Attitude and \\ Intention to Use Park-and-Ride)
}

Muhamad Nazri Borhan*, Norliza Mohd Akhir, Amiruddin Ismail \& Riza Atiq Abdullah O.K. Rahmat

ABSTRAK

Pemodelan persamaan struktur (SEM) merupakan satu teknik permodelan statistik lelurus dalam parameter yang sangat fleksibel dan boleh menguruskan sebilangan besar pemboleh ubah eksogen, endogen dan termasuk pemboleh ubah yang tidak diukur. Kebiasaannya, kaedah penganggaran yang digunakan dalam analisis pemodelan ini adalah penganggaran kebolehjadian maksimum (ML). Dalam kajian ini, model penggunaan park-and-ride (P\&R) dibangunkan untuk menganggar kesan langsung, kesan tidak langsung dan kesan keseluruhan terhadap fenomena yang dikaji. Berdasarkan kerangka konseptual kajian yang dicadangkan, model struktur penuh telah dicadangkan dan diuji, dan ramalan yang penting telah dikenal pasti berdasarkan kesignifikan secara statistik bagi semua pekali lintasan dalam model. Kajian ini menunjukkan bahawa hampir semua hubungan kausal adalah signifikan secara statistik. Implikasi setiap peramal turut dibincangkan di dalam kajian ini.

Kata kunci: Pemodelan persamaan struktur; P\&R; kebolehjadian maksimum

ABSTRACT

Structural equation modelling (SEM) is a modelling technique that can handle a large number of endogenous and exogenous variables, as well as latent variables specified as linear combinations of the observed variables. Usually, the estimation method used in the modelling analysis is the maximum likelihood (ML) estimation. In this study, the park-and-ride (P\&R) usage model was developed to estimate the direct effects, indirect effects and overall impact on the studied phenomenon. Based on the proposed conceptual framework, the full structured models were proposed and tested, thus the significant predictors were identified based on the statistical significance for all paths in the model. The findings revealed that almost all causal relationships were statistically significant. Implications for all predictors were also discussed in this study.

Keywords: Structural equation modelling; $P \& R$; maximum likelihood

\section{PENGENALAN}

Pusat pentadbiran bagi Kerajaan Persekutuan yang baharu, Putrajaya, merupakan sebuah bandar yang unik dari segi perspektif dasar pengangkutannya disebabkan matlamat utama adalah untuk menjadikan bandar ini bebas dari kesesakan dan menetapkan sasaran sebanyak $70 \%$ perjalanan di dalam bandar dengan menggunakan pengangkutan awam. Walau bagaimanapun, sasaran ini semakin sukar dicapai berdasarkan situasi sekarang yang lebih berpihak kepada penggunaan kenderaan persendirian yang telah memonopoli jalan-jalan utama di Putrajaya. Nisbah ragaman pengangkutan sekarang di antara kenderaan persendirian dan pengangkutan awam di Putrajaya adalah sebanyak 85:15 (Borhan et al. 2013; Nor et al. 2006). Antara perkhidmatan pengangkutan awam yang disediakan di Putrajaya adalah perkhidmatan P\&R yang mengandungi satu perjalanan kereta yang menggunakan kereta dari tempat tinggal pengguna hingga ke kawasan pinggir bandar Putrajaya di mana terletaknya stesen P\&R, seterusnya pengguna akan menggunakan pengangkutan awam seperti bas untuk meneruskan perjalanan ke kawasan bandar terutamanya lokasi perkerjaan pengguna (Bos et al. 2004). Matlamat penyediaan perkhidmatan $P \& R$ ini adalah untuk membantu pengguna dan pekerja di Putrajaya untuk menjadikan Putrajaya sebagai sebuah bandar yang bebas dari kesesakan.

Kajian ini menggunakan pemodelan persamaan struktur (SEM) yang merupakan satu teknik permodelan statistik lelurus untuk menganggar kesan langsung, kesan tidak langsung dan kesan keseluruhan terhadap penggunaan P\&R di Putrajaya. Satu perbezaan di antara SEM dan kaedah statistik lain dan kelebihan SEM adalah keupayaan untuk menganggar dan menguji hubungan antara peramal secara serentak. Berbanding dengan model linear yang lain di mana peramal hanya diwakili dengan satu pengukuran dan pengukuran ralat tidak dimodelkan. Manakala SEM membolehkan pengukuran lebih dari satu pengukuran untuk setiap peramal dan ralat turut dimasukkan ke dalam model pengukuran (Weston \& Gore 2006). Biddle dan Marlin (1987) menyatakan tentang SEM sebagai "teknik yang 
dicadangkan untuk meningkatkan keupayaan kita untuk membuat kesimpulan sebab dan akibat daripada data kajian lapangan". Penggunaan SEM telah banyak digunakan di dalam pelbagai bidang kajian (Ghozali 2008; Kline 2005). Manakala penggunaan SEM di dalam bidang kajian pengangkutan telah mula dikaji bermula pada tahun 1980 (Golob 2003).

Oleh yang demikian, matlamat utama kajian ini adalah untuk menyediakan rangka kerja asas dan strategi untuk mempertingkatkan tahap perkhidmatan pengangkutan awam yang telah sedia ada di Putrajaya seperti P\&R dengan menukarkan keinginan orang ramai daripada menggunakan kenderaan persendirian kepada pengangkutan awam. Model SEM yang dihasilkan akan diuji menggunakan penganggaran kebolehjadian maksimum (ML) untuk mendapat model akhir yang baik.

\section{KAEDAH KAJIAN}

PENGANGGARAN PARAMETER DALAM MODEL SEM

Model pengukuran adalah proses yang dilaksanakan sebelum membuat anggaran model struktur. Terdapat dua pendekatan yang telah dicadangkan oleh Anderson dan Gerbing (1988) dalam melaksanakan model anggaran SEM iaitu menggunakan model pengukuran dengan melakukan analisis faktor pengesahan, CFA (Confirmatory Factor Analysis) dan diikuti dengan anggaran model struktur lengkap. CFA adalah bertujuan menguji sama ada beban petunjuk signifikan terhadap pemboleh ubah pendam seperti yang diingini (Weston \& Gore 2006). Hassan dan Bakar (2008) menyatakan CFA dilakukan untuk menguji pengesahan pemboleh ubah pendam. Menurut Chen et al. (2007), kesahan menumpu dan kesahan mencapah perlu diuji dalam CFA. Tiga kriteria yang perlu dilihat dalam pengesahan menumpu seperti yang dicadangkan oleh Fornell dan Larcker (1981) iaitu: (1) Faktor pembebanan $(\lambda)$ bagi setiap item hendaklah signifikan dan nilainya mesti melebihi 0.5 . Terdapat juga pengkaji yang mencadangkan harus melebihi 0.7. Namun begitu kajian ini akan menggunakan nilai 0.5 sebagai nilai ambang; (2) Kebolehpercayaan gubahan (KG) bagi setiap konstruk hendaklah melebihi nilai 0.70; (3) Purata varians terekstrak, AVE (AVErage Variance Extract), bagi setiap konstruk haruslah melebihi 0.50 .

Pengesahan mencapah pula mengukur sejauh mana sesuatu konstruk itu berbeza dari konstruk-konstruk lain dengan diuji nilai punca kuasa dua AVE terhadap nilai korelasi antara konstruk (Ghozali 2008). Jika nilai AVE lebih tinggi dari nilai korelasi konstruk lain, maka ia menunjukkan pengesahan pembezaan yang baik bagi setiap konstruk yang digunakan (Chen et al. 2007).

\section{PENILAIAN KESESUAIAN MODEL SEM}

Bagi penganggaran ML, satu set statistik padanan diwujudkan dan ditetapkan sebagai ukuran padanan model atau ketepatan prediktif untuk menilai kesesuaian model yang dihasilkan (Hair et al. 2010). Statistik padanan perlu dipatuhi terlebih dahulu sebelum melihat kepada setiap hubungan secara spesifik. Fokus SEM adalah terhadap keseluruhan model dan ia menggunakan beberapa statistik padanan yang dapat menerangkan sejauh mana teori pengkaji dapat menerangkan data iaitu matriks kovarians yang tercerap antara pemboleh ubah yang dikaji seperti yang ditunjukkan di dalam Jadual 1.

JADUAL 1. Nilai indeks kesesuaian model yang diterima pakai

\begin{tabular}{lc}
\hline Statistik padanan & Julat indeks \\
\hline Khi-kuasa dua $\left(\chi^{2}\right)$ & Tidak berkaitan \\
Nilai- $p$ & $\leq 0.05$ \\
Khi-kuasa dua bernorma & $<3$ \\
Indeks padanan komparatif (CFI) & $\geq 0.90$ \\
Indeks Tucker-Lewis (TLI) & $\geq 0.90$ \\
RMSEA & $<0.08$ \\
\hline
\end{tabular}

\section{PENGUMPULAN DATA}

Kaedah pengumpulan data yang dijalankan ke atas responden melalui agihan borang soal selidik ke jabatan-jabatan kerajaan dan kementerian-kementerian serta premis-premis persendirian di Putrajaya. Borang soal selidik yang dihasilkan bertujuan untuk mendapat maklumat yang diperlukan daripada responden bagi kajian ini. Borang soal selidik ini terbahagi kepada tiga aspek utama iaitu:

\section{Bahagian A: Latar belakang responden;}

2. Bahagian B: Maklumat tentang perjalanan responden;

3. Bahagian $\mathrm{C}$ : Maklumat berdasarkan kepada model konseptual.

Pada Bahagian $\mathrm{C}$, responden akan ditanya berdasarkan kepada model konseptual. Pemilihan faktor-faktor yang digunakan di dalam model konseptual (Rajah 1) adalah berdasarkan tinjauan melalui kajian perpustakaan terhadap kajian lepas. Faktor kualiti perkhidmatan mempunyai sembilan item, faktor kesan alam sekitar mempunyai dua item, faktor sikap mempunyai tiga item dan faktor keinginan turut mempunyai dua item. Jadual 2 menerangkan item-item yang digunakan di dalam kajian ini bagi semua faktor.

Sebanyak 500 borang soal selidik telah diagihkan dan sebanyak 233 telah diterima semula. Walau bagaimanapun sebanyak 22 borang terpaksa ditolak dari dilakukan analisis

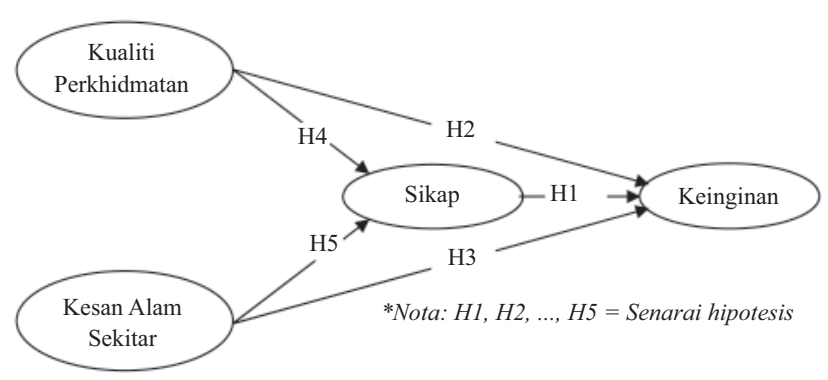

RAJAH 1. Kerangka konseptual kajian penggunaan P\&R 
JADUAL 2. Faktor dan item yang digunakan di dalam kajian ini

\begin{tabular}{ll}
\hline Faktor & Item \\
\hline Kualiti Perkhidmatan (KP) & Ketepatan waktu bas tiba (KP1); \\
& Keselamatan di perhentian bas/terminal (KP2); \\
& Keselamatan ketika di dalam bas (KP3); \\
& Perkhidmatan pelanggan (KP4); \\
& Maklumat masa perjalanan dan laluan bas (KP5); \\
& Kebersihan bas (KP6); \\
& Penyediaan sistem pembelian tiket yang sistematik (KP7); \\
& Penyediaan tempat menyimpan barang di dalam bas (KP8); \\
& Penyediaan laluan khas untuk bas (KP9) \\
& Penggunaan kereta menyumbang kepada pencemaran alam sekitar (KAS1); \\
& Penggunaan kereta menyumbang kepada kesesakan (KAS2) \\
& Menggunakan P\&R satu idea yang bijak untuk mengurang kesesakan (S1); \\
Kesan Alam Sekitar (KAS) & Menggunakan P\&R satu langkah yang baik mengurangkan kesesakan (S2); \\
Sikap (KP) & Saya suka idea untuk menggunakan P\&R (S3) \\
& Saya berniat menggunakan P\&R untuk mengurangkan kesesakan di Putrajaya (K1); \\
& Saya akan menggunakan P\&R ke tempat kerja selepas ini (K2). \\
Keinginan (K) &
\end{tabular}

seterusnya kerana borang tersebut tidak diisi sepenuhnya oleh responden. Oleh itu, hanya 211 borang soal selidik diterima untuk dilakukan analisis. Maklumat demografi responden adalah seperti di dalam Jadual 3. Bagi skala pengukuran untuk soal selidik ini, skala Likert 7-skala dengan skala 1 $=$ 'Sangat Tidak Setuju' dan skala $7=$ 'Sangat Setuju' telah digunapakai.

JADUAL 3. Demografik bagi responden

\begin{tabular}{llcc}
\hline & & Kekerapan & Peratus \\
\hline Umur & 29 tahun dan ke bawah & 119 & 56.4 \\
& $30-39$ & 56 & 26.5 \\
& $40-49$ & 17 & 8.1 \\
\multirow{5}{*}{ Jantina } & 50 tahun dan ke atas & 19 & 9.0 \\
& Lelaki & 119 & 56.4 \\
& Perempuan & 92 & 43.6 \\
\multirow{5}{*}{ Pekerjaan } & 48 & 22.7 \\
& SPM & 74 & 35.1 \\
& Diploma & 67 & 31.8 \\
& Ijazah & 22 & 10.4 \\
& Pjazah tinggi & 119 & 56.4 \\
& Pentadbiran & 28 & 13.3 \\
& Juruteknik & 64 & 30.3 \\
& Profesional & 86 & 40.8 \\
& RM2000 dan ke bawah & 62 & 29.4 \\
& RM2001-RM3000 & 63 & 29.8 \\
\hline
\end{tabular}

\section{KEPUTUSAN ANALISIS STATISTIK}

Dalam bahagian ini akan menerangkan tentang pemodelan yang dihasilkan berdasarkan data yang diperolehi daripada kajian soal yang telah dilakukan di pusat petadbiran Putrajaya. Jumlah saiz sampel yang digunakan dalam kajian ini adalah sebanyak 211 sampel. Rajah 1 memaparkan kerangka konseptual model struktur yang akan diuji iaitu model penggunaan perkhidmatan P\&R bersandarkan faktor-faktor yang menunjukkan hubungan kausal antara setiap konstruk yang telah dihipotesiskan. Dalam proses membangunkan model SEM dalam kajian ini, kaedah dua pendekatan (model pengukuran dan model struktur) digunakan yang telah dicadangkan dan disyorkan oleh Hair et al. (1998) dan Anderson dan Garbing (1988) untuk menilai kesahan konstruk, kesesuaian model dan untuk menguji hipotesis. Berikut merupakan hipotesis-hipotesis yang dicadangkan iaitu: Hipotesis dinyatakan seperti berikut.

H1: Terdapat hubungan positif antara kualiti perkhidmatan ke arah menggunakan P\&R melalui sikap.

$\mathrm{H} 2$ : Terdapat hubungan positif antara kesan alam sekitar ke arah menggunakan P\&R melalui sikap.

H3: Terdapat hubungan positif antara kualiti perkhidmatan dan keinginan untuk menggunakan P\&R.

H4: Terdapat hubungan positif antara kesan alam sekitar dan keinginan untuk menggunakan P\&R.

H5: Terdapat hubungan positif antara sikap dan keinginan untuk menggunakan P\&R.

\section{ANALISIS MODEL PENGUKURAN DAN PENILAIAN KESAHAN}

Langkah pertama dalam penghasilan model SEM iaitu membangunkan model pengukuran serta melakukan kesahan menumpu. Bagi mengukur skala kesahan untuk model pengukuran, kaedah CFA digunakan untuk menilai kesahihan konstruk dari teori pengukuran yang telah dicadangkan. Kaedah CFA untuk menghapus atau menggugurkan item-item di dalam konstruk yang mempunyai faktor beban yang kurang daripada 0.5 atau yang tidak signifikan (Ambak et al. 2010; Hair et al. 1998).

Jadual 4 menunjukkan bahawa semua nilai faktor pembebanan bagi item melebihi 0.5 dan signifikan pada nilai $-p<0.01$. Analisis KG menunjukkan kesemua konstruk mempunyai nilai KG melebihi nilai ambang yang disyorkan 
0.7. Ini menunjukkan model yang dihasilkan mempunyai konstruk-konstruk yang sah serta boleh dipercayai kerana memenuhi syarat minimum kesahan menumpu yang telah ditetapkan. Tambahan pula, nilai AVE bagi setiap konstruk juga melebihi nilai yang boleh diterima iaitu 0.5 . Selain daripada itu, nilai alfa Cronbach yang diperolehi bagi semua konstruk menunjukkan nilai yang melebihi nilai minimum iaitu 0.7 seperti yang disyorkan oleh Nunnally (1978).

JADUAL 4. Keputusan analisis kesahan menumpu bagi model kajian

\begin{tabular}{lcccc}
\hline Konstruk dan item & $\begin{array}{c}\text { Faktor } \\
\text { pembebanan }\end{array}$ & KG & AVE & $\alpha$ Cronbach \\
Kualiti & & 0.912 & 0.542 & 0.912 \\
Perkhidmatan (KP) & & & & \\
\hline
\end{tabular}

\begin{tabular}{lcccc}
\hline KP1 & $0.625(t=9.15)$ & & \\
KP2 & $0.737(t=13.25)$ & & \\
KP3 & $0.826(t=10.63)$ & & \\
KP4 & $0.854(t=9.70)$ & & \\
KP5 & $0.864(t=9.82)$ & & & \\
KP6 & $0.536(t=5.73)$ & & & \\
KP7 & $0.513(t=6.56)$ & & & \\
KP8 & $0.697(t=8.08)$ & & & \\
KP9 & $0.865(t=9.15)$ & & \\
Kesan Alam & & & \\
Sekitar (KAS) & & & \\
KAS1 & $0.687(t=6.02)$ & & & \\
KAS2 & $0.961(t=7.03)$ & & & \\
Sikap (S) & & 0.890 & 0.736 & 0.841 \\
S1 & $0.927(t=10.75)$ & & \\
S2 & $0.980(t=10.87)$ & & & \\
S3 & $0.622(t=10.76)$ & & \\
Keinginan (K) & & 0.819 & 0.700 & 0.797 \\
K1 & $0.960(t=12.45)$ & & \\
K2 & $0.691(t=7.97)$ & & & \\
\hline
\end{tabular}

Bagi menilai kesahan mencapah adalah melalui cadangan dari Fornell dan Larcker (1981) yang menyatakan punca-kuasa dua AVE bagi setiap konstruk perlu melebihi nilai korelasi antara konstruk itu dengan mana-mana konstruk lain. Nilai kesahan yang tinggi akan membuktikan sesuatu konstruk adalah unik dan sah. Nilai AVE bagi setiap konstruk akan dipunca-kuasa duakan dan dibandingkan dengan nilai korelasi antara konstruk. Hasil analisis menunjukkan nilai punca-kuasa dua AVE bagi konstruk KS, KAS, S dan $\mathrm{K}$ masing-masing adalah $0.736,0.835,0.858$ dan 0.837 . Manakala nilai korelasi antara konstruk ialah 0.239 (KP $\mathrm{KAS}), 0.194(\mathrm{KP} \leftrightarrow \mathrm{S}), 0.306(\mathrm{KP} \leftrightarrow \mathrm{K}), 0.403(\mathrm{KAS} \leftrightarrow$ $\mathrm{S}), 0.214(\mathrm{KAS} \leftrightarrow \mathrm{K})$ dan $0.526(\mathrm{~S} \leftrightarrow \mathrm{K})$. Ini menunjukkan hasil punca-kuasa dua AVE bagi setiap konstruk mempunyai nilai yang tinggi berbanding nilai korelasi antara konstruk, maka kesahan menumpu telah memenuhi syaratnya. Jadual 5 menunjukkan ringkasan kesahan mencapah bagi model pengukuran bagi penggunaan $\mathrm{P} \& \mathrm{R}$.
JADUAL 5. Keputusan analisis korelasi antara konstruk dan kesahan mencapah bagi model kajian

\begin{tabular}{lccccccc}
\hline & Min & SP & AVE & KP & KAS & S & K \\
\hline KP & 5.18 & 1.10 & 0.542 & $0.736^{*}$ & & & \\
KAS & 4.98 & 1.25 & 0.698 & $0.239^{* *}$ & $0.835^{*}$ & & \\
S & 4.56 & 1.45 & 0.736 & $0.194^{* *}$ & $0.403^{* *}$ & $0.858^{*}$ & \\
K & 4.18 & 1.40 & 0.700 & $0.306^{* *}$ & $0.214^{* *}$ & $0.526^{* *}$ & $0.837^{*}$ \\
\hline
\end{tabular}

Nota: $\mathrm{SP}=$ Sisihan piawai; *Nilai bagi kesahan mencapah bagi setiap konstruk; **Nilai korelasi antara konstruk pada nilai $-\mathrm{p}<0.01$.

\section{ANALISIS MODEL STRUKTUR DAN PENGUJIAN HIPOTESIS}

Menggunakan model pengukuran yang memenuhi semua syarat bagi kesahan menumpu dan dan kesahan mencapah, model struktur lengkap telah dibangunkan berdasarkan kerangka konseptual kajian untuk diuji dan menilai kepentingan dan kekuatan perhubungan kausal masingmasing di dalam model. Hasil analisis model struktur lengkap bagi penggunaan P\&R adalah seperti yang ditunjukkan dalam Rajah 2. Indeks kesesuaian bagi model struktur lengkap pula adalah seperti yang ditunjukkan dalam Jadual 6.

Secara keseluruhan, indeks kesesuaian bagi model yang dihasilkan dapat memenuhi julat indeks kesesuaian yang ditetapkan. Semakan terhadap output analisis mendapati bahawa tiada anggaran yang tidak munasabah dan pekalipekali regresi berada dalam julat yang dapat diterima. Selain itu, tidak terdapat varians yang bernilai negatif dan nilai-nilai matriks ralat piawai juga berada dalam julat yang dicadangkan

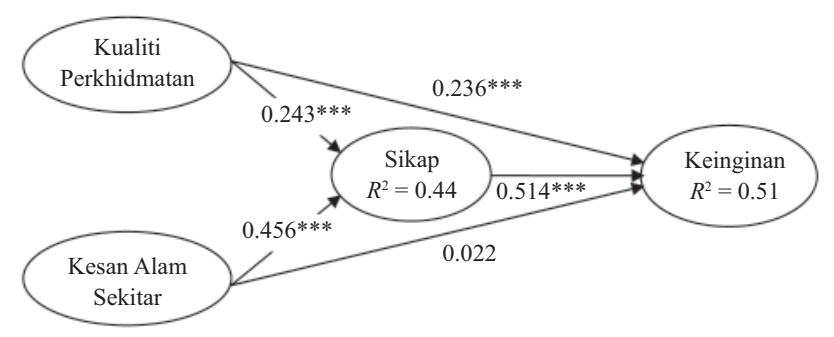

RAJAH 2. Keputusan bagi model struktur lengkap kajian.

$$
\text { Nota: } * * p<.01 ; * * * p<.001 \text {. }
$$

JADUAL 6. Statistik padanan model struktur $(n=211)$

\begin{tabular}{|c|c|c|}
\hline Statistik padanan & $\begin{array}{c}\text { Julat } \\
\text { indeks }\end{array}$ & $\begin{array}{l}\text { Nilai } \\
\text { kajian }\end{array}$ \\
\hline \multicolumn{3}{|l|}{ Indeks padanan mutlak CMIN } \\
\hline Khi-kuasa dua (2) & Tidak berkaitan & 152.074 \\
\hline Nilai- $p$ & $\leq 0.05$ & $<0.001$ \\
\hline dk (darjah kebebasan) & Tidak berkaitan & 87 \\
\hline RMSEA & $<0.08$ & 0.06 \\
\hline \multicolumn{3}{|l|}{ Indeks padanan tokokan } \\
\hline Indeks padanan komparatif (CFI) & $\geq 0.90$ & 0.972 \\
\hline Indeks Tucker-Lewis (2) & $\geq 0.90$ & 0.962 \\
\hline \multicolumn{3}{|l|}{ Indeks padanan parsimoni } \\
\hline Khi-kuasa dua bernorma ( $\mathrm{cmin} / \mathrm{dk})$ & $<3$ & 1.748 \\
\hline
\end{tabular}


oleh Hair et al. (2010) dan Bollen (1989). Min korelasi berganda kuasa dua, SMC (Square Mean Correlation) turut melebihi nilai ambang yang dicadangkan oleh kebanyakan penyelidik iaitu 0.50 (Ab Hamid et al. 2013; Chen et al. 2007). Ini menunjukkan bahawa lebih daripada $50 \%$ varians dapat diterangkan oleh konstruk daripada pemboleh ubah tercerap berbanding dengan ralatnya. Ini juga memberikan sokongan terhadap kesahan konstruk. Oleh yang demikian, berdasarkan keputusan kajian, kesemua pekali lintasan diuji pada nilai alfa $\alpha=0.05$, memberikan keputusan yang signifikan dengan nilai $-p<0.05$ kecuali pekali lintasan kesan alam sekitar terhadap keinginan yang tidak signifikan. Pekali lintasan yang tidak signifikan digugurkan daripada model struktur penggunaan P\&R. Oleh yang demikian, model berkenaan dapat diwakilkan melalui persamaan-persamaan berikut:

$$
\begin{aligned}
& \eta_{1}=0.514 \eta_{2}+0.236 \xi_{1}+\zeta_{2} \\
& \eta_{2}=0.243 \xi_{1}+0.456 \xi_{2}+\zeta_{1}
\end{aligned}
$$

Dengan $\eta_{1}$ ialah Keinginan, $\eta_{2}$ ialah Sikap, $\xi_{1}$ ialah Kualiti Perkhidmatan, $\xi_{2}$ ialah Kesan Alam Sekitar dan $\zeta_{1}$, $\zeta_{2}$ ialah Ralat.

Berdasarkan keputusan kajian, dapat diperhatikan bahawa keinginan menggunakan perkhidmatan pengangkutan awam seperti P\&R di Putrajaya diramalkan secara signifikan oleh sikap (pemberat regresi, $\beta=0.514$ ) dan diikuti oleh kualiti perkhidmatan $(\beta=0.238)$. Hubungan sikap dan kualiti perkhidmatan terhadap keinginan mempunyai hubungan yang positif dan ini menyokong hipotesis $\mathrm{H} 1$ dan H2. Manakala hipotesis, H3 untuk meramalkan kesan alam sekitar dilihat tidak menyokong dan tidak memberikan hubungan yang signifikan kepada keinginan. Selanjutnya, kualiti perkhidmatan dilihat memberikan hubungan yang signifikan terhadap sikap dengan pemberat regresi, regresi, $\gamma=0.243$, manakala kesan alam sekitar mempengaruhi sikap secara signifikan dengan pemberat regresi, $\gamma=0.456$ dan ini menunjukkan hipotesis $\mathrm{H} 4$ dan $\mathrm{H} 5$ disokong dan diterima. Jadual 7 menunjukkan ringkasan terhadap pengujian hipotesis bagi model struktur penggunaan P\&R.

\begin{tabular}{|c|c|c|c|}
\hline Perhubungan kausal & Pekali lintasan & Nilai t & Keputusan \\
\hline H1: Sikap $\rightarrow$ Keinginan & 0.514 & 5.006 & Terima \\
\hline $\begin{array}{l}\text { H2: Kualiti perkhidmatan } \rightarrow \\
\text { Keinginan }\end{array}$ & 0.238 & 3.329 & Terima \\
\hline $\begin{array}{l}\text { H3: Kesan alam sekitar } \rightarrow \\
\text { Digugurkan } \\
\text { Keinginan }\end{array}$ & -0.022 & 0.3 & 03 \\
\hline $\begin{array}{l}\text { H4: Kualiti perkhidmatan } \rightarrow \\
\text { Sikap }\end{array}$ & 0.243 & 3.617 & Terima \\
\hline $\begin{array}{l}\text { H5: Kesan alam sekitar } \rightarrow \\
\text { Sikap }\end{array}$ & 0.456 & 4.670 & Terima \\
\hline
\end{tabular}

JADUAL 7. Ringkasan terhadap pengujian hipotesis model kajian 
Keutamaan bagi meningkatkan kualiti perkhidmatan boleh lakukan berdasarkan pemberat regrasi bagi setiap faktor di dalam konstruk kepercayaan. Pihak yang bertanggungjawab seperti kerajaan dan Perbadanan Putrajaya harus terlibat dalam peningkatan kualiti perkhidmatan untuk meningkatkan kepercayaan pengguna pada masa hadapan. Aspek yang memiliki pemberat yang tinggi seperti penyediaan laluan bas, penyediaan maklumat masa perjalanan dan laluan bas, ketepatan waktu bas tiba ke destinasi dan tahap keselamatan pengguna ketika menggunakan perkhidmatan $\mathrm{P} \& \mathrm{R}$, manakala aspek lain yang turut perlu dipertimbangkan seperti pembelian tiket sistematik, kebersihan dan keselesaan, penyediaan ruang untuk meletak barang di dalam bas serta meningkat kualiti perkhidmatan pelanggan.

Sementara itu, kesan alam sekitar tidak memberikan kesan yang signifikan kepada keinginan untuk menggunakan perkhidmatan P\&R. Ini menunjukkan, secara terus orang ramai tidak merasa bimbang terhadap kesan pencemaran yang dihasilkan oleh kenderaan persendirian ke atas alam sekitar. Ini telah menyebabkan mereka tiada keinginan untuk menggunakan perkhidmatan P\&R bagi mengurangkan masalah alam sekitar kesan daripada penggunaan kenderaan persendirian. Walau bagaimanapun, kesan alam sekitar dilihat dapat memberi kesan kepada keinginan secara tidak langsung melalui pemboleh ubah sikap. Ini menunjukkan semakin ramai pemandu kenderaan persendirian bimbang tentang akibat masalah alam sekitar yang dihasilkan oleh kenderaan mereka dari dalam diri mereka sendiri, maka sikap mereka akan lebih positif terhadap keinginan untuk menggunakan P\&R.

\section{KESIMPULAN}

Di banyak negara termasuk Malaysia, kesesakan lalu lintas dan kegagalan sistem pengangkutan awam telah menerima banyak perhatian dari pelbagai pihak untuk mencari jalan penyelesaian terhadap kedua-dua masalah tersebut. Pelbagai usaha meningkatkan taraf pengangkutan awam telah dilakukan oleh kerajaan untuk menyesuaikan keadaan kepada keperluan pembangunan negara selari dengan matlamat untuk menjadikan Malaysia sebuah negara maju pada tahun 2020. Dalam kajian ini, model penggunaan perkhidmatan P\&R di Putrajaya dengan menggunakan pendekatan permodelan persamaan struktur dihasilkan untuk menganggar kesan langsung, kesan tidak langsung dan kesan keseluruhan terhadap fenomena yang dikaji.

Kesimpulannya, model persamaan struktur untuk mengkaji keinginan menggunakan perkhidmatan P\&R di Putrajaya dapat diramal dan dipengaruhi secara kuat oleh pemboleh ubah sikap yang positif yang boleh dipengaruhi oleh peningkatan kualiti perkhidmatan dan juga kebimbangan terhadap alam sekitar. Peningkatan kualiti perkhidmatan juga turut memberikan kesan secara terus kepada keinginan orang ramai untuk menggunakan perkhidmatan P\&R. Walau bagaimanapun, dengan hanya meningkatkan kualiti pengangkutan awam sahaja juga tidak mendorong anjakan pekerja di Putrajaya kepada pengangkutan awam seperti P\&R. Ini kerana terdapat faktor lain yang mendorong penggunaan kenderaan persendirian di Putrajaya seperti penyediaan tempat letak kenderaan percuma di premis atau tempat kerja pengguna. Menurut Hess (2001), dengan mengenakan bayaran parkir di tempat kerja mampu mengurangkan bilangan kereta yang dipandu secara bersendirian dan akan meningkatkan kecekapan penggunaan pengangkutan awam. Pada masa yang sama, pekhidmatan pengangkutan awam perlu ditingkatkan seperti mengurangkan masa menunggu pengguna dan perkhidmatan yang boleh dipercayai. Oleh itu, langkah penyekatan permintaan seperti mengenakan bayaran tempat letak kereta perlu dilakukan bagi mengurangkan penggunaan kereta di Putrajaya. Oleh itu, untuk kajian seterusnya, faktor berdasar halangan dari segi kewangan seperti mengenakan bayaran ke kawasan bandar dan mengenakan bayaran tempat letak kenderaan di tempat kerja perlu dikaji bagi menggalakkan pekerja menggunakan pengangkutan awam seperti P\&R dan bas di Putrajaya.

\section{PENGHARGAAN}

Penulis ingin mengucapkan terima kasih kepada Jabatan Kejuruteraan Awam dan Struktur, Fakulti Kejuruteraan dan Alam Bina, Universiti Kebangsaan Malaysia dan Perbadanan Putrajaya di atas bantuan untuk melaksanakan kajian ini.

RUJUKAN

Ab Hamid, M. R., Mustafa, Z., Mohd. Suradi, N. R., Idris, F. \& Mokhtar, A. 2013. Perbandingan anggaran parameter terhadap model kecemerlangan prestasi institut pengajian tinggi (IPT) bersandarkan nilai teras: Pendekatan penganggaran kebolehjadian maksimum (ML) dan kuasa dua terkecil separa (PLS). Sains Malaysiana 42(8): 1159-1166.

Ajzen, I. \& Fishbein. M. 1980. Understanding Attitudes and Predicting Social Behaviour. Englewood Cliffs, New Jersey: Prentice-Hall.

Ambak, K., Ismail, R., Abdullah, R. A. \& Borhan, M. N. 2010. Prediction of helmet use among malaysian notorcyclist using structural equation modeling. Australian Journal of Basic and Applied Sciences 4(10): 5263-5270.

Anderson, J. C. \& Gerbing, D. W. 1988. Structural equation modeling in practice: A review and recommended two-step approach. Psychological Bulletin 103(3): 411-423.

Biddle, B. J. \& Marlin, M. M. 1987. Causality, confirmation, credulity, and structural equation modeling. Child Development 58(1): 4-17.

Bollen, K. A. 1989. Structural Equations with Latent Variables. New York: John Wiley \& Sons.

Borhan, M. N., Rahmat, R. A. A. O. K., Ismail, A. \& N. M. Akhir. 2013. Kesan masa perjalanan bas dan bayaran tempat letak kereta terhadap penggunaan pengangkutan awam di Putrajaya. Jurnal Teknologi 61(1): 67-71. 
Bos, I. D. M., Van der Heijden, R. E. C. M., Molin, E. J. E. \& Timmermans, H. J. P. 2004. The choice of park and ride facilities: An analysis using a context-dependent hierarchical choice experiment. Environment and Planning A 36: 1673-1686.

Chen, C. D., Fan, Y. W. \& Farn, C. K. 2007. Predicting electronic toll collection service adoption: An integration of the Technology Acceptance Model and the Theory of Planned Behavior. Transportation Research Part $C$ 15: 300-311.

De Groot, J. \& Steg, L. 2007. General beliefs and the Theory of Planned Behavior: The role of environmental concerns in the TPB. Journal of Applied Social Psychology 37(8): 1817-1836.

Fornell, C. \& Larcker, D. F. 1981. Evaluating structural equations with unobservable variables and measurement error. Journal of Marketing Research 18: 39-50.

Ghozali, I. 2008. Model Persamaan Structural: Konsep dan Aplikasi Dengan Program AMOS 16.0. Semarang: Badan Penerbitan Universitas Diponegoro.

Golob, T. F. 2003. Structural equation modeling for trAVEl behavior research. Transportation Research Part B 37: $1-25$.

Hair, J., Anderson, R. E., Tatham, R. L. \& Black, W. C. 1998. Multivariate Data Analysis. $5^{\text {th }}$ edition. Upper Saddle River, N.J.: Prentice-Hall.

Hair, J. F., Black, W. C., Babin, B. J. \& Anderson, R. E. 2010. Multivariate Data Analysis. 7 ed. Upper Saddle River, New Jersey: Prentice Hall.

Muhamad Nazri Borhan*, Norliza Mohd Akhir, Amiruddin Ismail \& Riza Atiq Abdullah O.K. Rahmat

Pusat Penyelidikan Pengangkutan Bandar Mapan (SUTRA)

Jabatan Kejuruteraan Awam dan Struktur

Fakulti Kejuruteraan dan Alam Bina

Universiti Kebangsaan Malaysia

43600 UKM Bangi, Selangor, Malaysia

*Penulis koresponden; emel: mnazri_borhan@ukm.edu.my

Tarikh serahan: 13 Ogos 2014

Tarikh terima: 6 Januari 2015
Hassan, S. A. \& Bakar, K. A. 2008. Exploratory versus confirmatory factor analysis. Prosiding Seminar Penyelidikan dan Pembangunan Sumber Manusia 2008. 1-15.

Hess, D. B. 2001. The effect of free parking on commuter mode choice: Evidence from travEl diary data. Transportation Research Record 1753: 35-42.

Kline, R. B. 2005. Principles and Practice of Structural Equation Modeling. $2^{\text {nd }}$ edition. New York: The Guilford Press.

Nor, N. G. M., Nor, A. R. M. \& Abdullah, A. Z. 2006. Predicting the impact of demand- and supply-side measures on bus ridership in Putrajaya, Malaysia. Journal of Public Transportation 9(5): 57-70.

Nunnally, J. 1978. Psychometric Theory. $2^{\text {nd }}$ edition. New York: McGraw-Hill.

Parasuraman, A., Zeithaml, V. A. \& Berry, L. L., 1985. A conceptual model of service quality and its implications for future research. Journal of Marketing 49(4): 41.

Transportation Research Board (TRB). 1999. A Handbook for Measuring Customer Satisfaction and Service Quality. Transit Cooperative Research Program (TCRP). Report 47. National Research Council, Washington, DC.

Weston, R. \& Gore, P. A. 2006. A brief guide to structural equation modeling. The Counseling Psychologist 34: 719-751. 